\title{
Erratum to: Dissolved nitrogen release from coarse and amphipod-produced fine particulate organic matter in freshwater column
}

\author{
Quynh Nga Le $^{1} \cdot$ Manabu Fujii $^{1} \cdot$ Chihiro Yoshimura $^{1} \cdot$ Klement Tockner $^{2,3}$
}

Published online: 7 January 2016

(C) The Japanese Society of Limnology 2016

\section{Erratum to: Limnology (2016) 17:33-46 \\ DOI 10.1007/s10201-015-0458-3}

Unfortunately, Fig. 5 was published with error in the initial publication of the article. The corrected Fig. 5 is published with this erratum.

The online version of the original article can be found under doi:10.1007/s10201-015-0458-3.

Quynh Nga Le

quynhnga.1.aa@m.titech.ac.jp

1 Department of Civil Engineering, Tokyo Institute of Technology, 2-12-1-M1-4 Ookayama, Tokyo 152-8552, Japan

2 IGB, Leibniz-Institute of Freshwater Ecology and Inland Fisheries, Müggelseedamm 310, 12587 Berlin, Germany

3 Institute of Biology, Free University of Berlin, Müggelseedamm 310, 12587 Berlin, Germany 
Fig. $5 \mathrm{NO}_{2}{ }^{-}+\mathrm{NO}_{3}{ }^{-}$release rate (mean $\pm \mathrm{SD}, n=3$ ) from CPOM, L-FPOM, and M-FPOM,

standardized to the dry mass of POM. Error bars (SD) are shown on the upper side of the mean (some bars are not visible because they are too small). Note that the $\mathrm{NO}_{2}{ }^{-}+\mathrm{NO}_{3}{ }^{-}$release rates on day 14 were plotted at day 11.5 , because the rates express the average in week 2
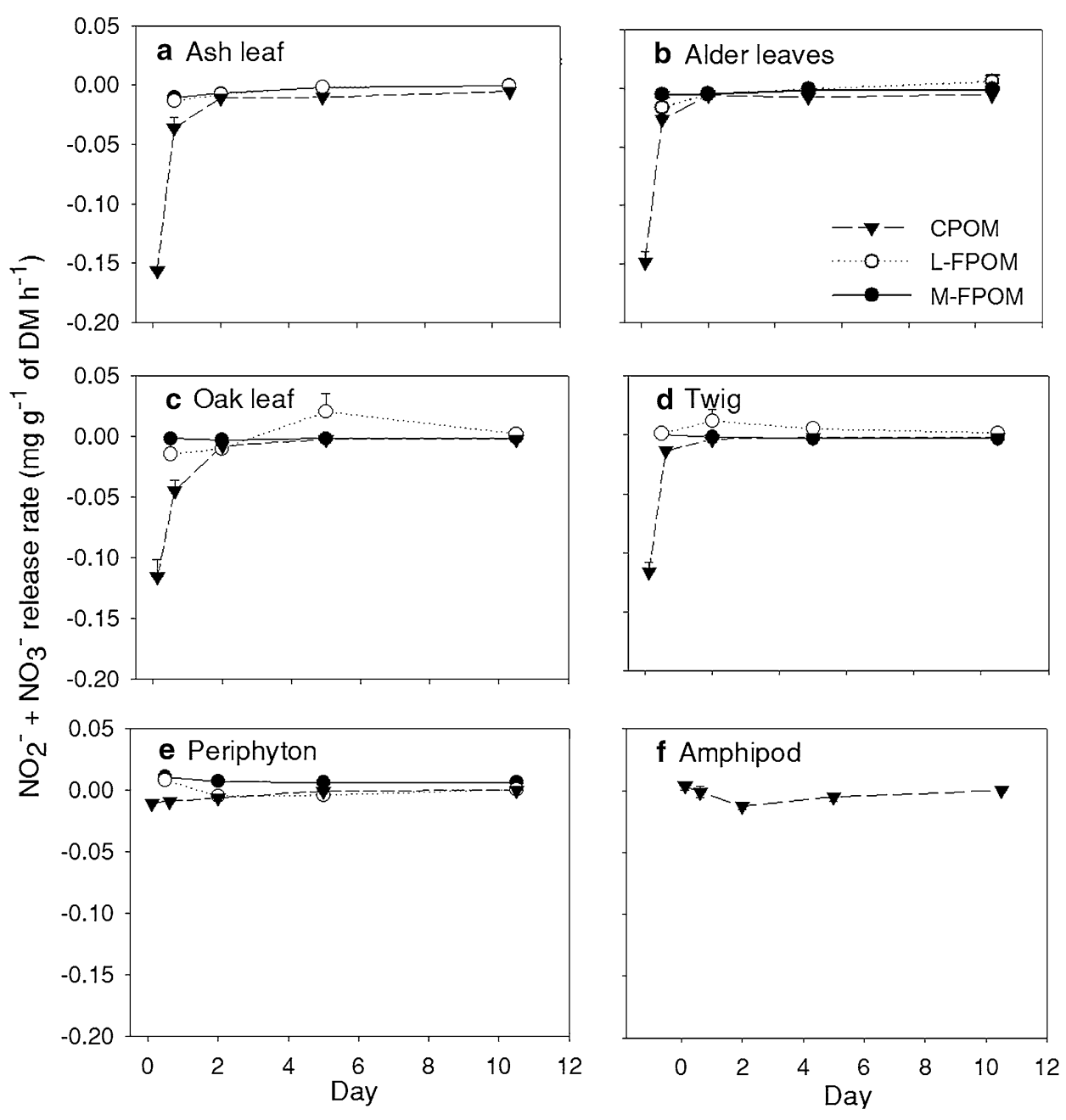